OPEN ACCESS

Edited by:

Bao-jun Sun,

Institute of Zoology, Chinese Academy of Sciences (CAS), China

Reviewed by:

Wei Chen,

Anhui University, China

Zhiqiang Guo,

Hainan University, China

*Correspondence:

Tian Zhao

zhaotian@cib.ac.cn

Specialty section:

This article was submitted to

Conservation and Restoration

Ecology,

a section of the journal

Frontiers in Ecology and Evolution

Received: 01 December 2021

Accepted: 03 January 2022

Published: 27 January 2022

Citation:

Zhao C, Jiang J, Xie F, Li C and

Zhao T (2022) Assessment

of Amphibians Vulnerability to Climate

Change in China.

Front. Ecol. Evol. 10:826910.

doi: 10.3389/fevo.2022.826910

\section{Assessment of Amphibians Vulnerability to Climate Change in China}

\author{
Chunlin Zhao ${ }^{1,2}$, Jianping Jiang ${ }^{1}$, Feng Xie' ${ }^{1}$, Cheng Li $^{1}$ and Tian Zhao ${ }^{1 *}$ \\ ${ }^{1}$ CAS Key Laboratory of Mountain Ecological Restoration and Bioresource Utilization and Ecological Restoration Biodiversity \\ Conservation Key Laboratory of Sichuan Province, Chengdu Institute of Biology, Chinese Academy of Sciences, Chengdu, \\ China, ${ }^{2}$ Key Laboratory of Bio-Resources and Eco-Environment (Ministry of Education), College of Life Sciences, Sichuan \\ University, Chengdu, China
}

Global climate change is considered to be one of the main threats to organisms. As poikilothermic animals, amphibians are in particular sensitive because they cannot adapt to the dramatic climate change through active physiological regulation. Using 104 representative species, the present study conducted an assessment of amphibians vulnerability to climate change in China through the combination of two approaches. Specifically, 18 vulnerability criteria belonging to five categories (i.e., thermal tolerance, individual reproductive, population diffusion and diversity, food and habitat, and climate conditions) were first selected and scored based on literatures and experts opinions. Species were then ranked into three levels of climate change vulnerability (i.e., high, moderate, and low) by calculating vulnerability scores and conducting natural breaks analyses, as well as performing a principal coordinate analysis (PCOA) and k-means cluster analyses, respectively. To integrate the two results, a matrix with the ranks from each result was developed to produce a final integrated list. Our results indicated that the 104 amphibian species were classified into three types by natural breaks, with 54 low vulnerable species, 41 moderately vulnerable species, and nine highly vulnerable species. Based on the results of PCOA and $k$-means cluster analyses, five species were highly vulnerable, 38 species were moderately vulnerable, and 61 species were low vulnerable. The combination of the two ranks suggested that 36 species such as Hyla tsinlingensis and Liangshantriton taliangensis were of low vulnerability, 54 species such as Echinotriton chinhaiensis and Hynobius chinensis were of moderate vulnerability, and 14 species such as Ichthyophis kohtaoensis and Zhangixalus prasinatus were of high vulnerability. Overall, our results indicated that climate change could have strong potential effects on amphibians in China. And the highly vulnerable species such as Ichthyophis kohtaoensis, Zhangixalus prasinatus, and Theloderma corticale should be the priority in future conservation activities.

Keywords: climate change, amphibians, natural breaks, vulnerability assessment, conservation 


\section{INTRODUCTION}

Biodiversity and ecosystems have been in the Anthropocene phase due to the expansion of human population since the twentieth century (Elmqvist et al., 2013). Accordingly, global changes (e.g., land use change, habitat fragmentation, biological invasions, and climate change) induced by human activities have caused dramatic impacts on the biological attributes of ecosystems (Gaston et al., 2010; Bellard et al., 2012). This is considered to be the main reason leading to the changes of organisms. For instance, previous studies indicated that global changes induced the distribution of terrestrial organisms (e.g., birds, mammals, and plants) to be shifted from low to high elevations/latitudes (Chen I.C. et al., 2011), less diverse of reef communities (Hoegh-Guldberg et al., 2007), and the change of birds species composition in tropical forest ecosystems (Pounds et al., 1999). As poikilothermic animals, amphibians are considered to be more susceptible to global changes (Carey and Alexander, 2003; Li et al., 2013). This is because they have a group of specific life history traits, such as permeable skin, eggs without shell, and aquatic living larvae but terrestrial living adults (Wake and Vredenburg, 2008). Indeed, global changes have caused the decline of one third (32\%) of the amphibian populations all over the world (IUCN, 2016). This is especially true in China, as a previous study indicated that around $43 \%$ of the amphibians were strongly affected by global changes, including one extinct species, one regional extinct species, and 176 under threatened species in China (Jiang et al., 2016).

Climate change is one of the most important facets of global changes affecting the survival of amphibians (Grimm et al., 2008; Wang and Feng, 2013). Specifically, the increasing of global mean temperature can induce the phenological shifts, and thus affect amphibians life history traits (e.g., breeding time; Parmesan, 2007, hibernation; Reading, 2007; Sheridan and Bickford, 2011; Gao et al., 2015). Moreover, the fluctuation of precipitation can strongly disturb amphibians habitat quality, tadpoles metamorphosis, as well as adults population dynamics (Lowe, 2012). In addition, recent works have demonstrated that amphibians distribution patterns can be also altered by climate change (e.g., Odorrana hainanensis; Huang et al., 2017, Andrias davidianus; Zhao et al., 2020). However, these studies only focused on single species, integrative work is still needed to evaluate the vulnerability of a group of amphibian species to climate change at both regional and global scales (but see Li et al., 2013).

The vulnerability of a species to climate change is the extent to which is threatened or extinct owing to climate change (Dawson et al., 2011). Therefore, it is typically assessed by selecting criteria related to species exposure, sensitivity, and adaptive capacity to climate change (Williams et al., 2008; Foden et al., 2013). Specifically, exposure is the degree of climate change likely to be experienced by species. It is usually assessed based on scenario projections from general circulation models (GCMs), and is strongly depended on external factors such as temperature change, precipitation fluctuation, severe weather events, and sea level rise (Dawson et al., 2011; Rowland et al., 2011). Sensitivity refers to the degree of change of species survival, physiology, behavior, population dynamics, or life history when facing the stress of climate change. It can be assessed by empirical, model, and observational studies (Dawson et al., 2011; Rowland et al., 2011). Adaptive capacity is the ability of species to adapt to climate change through persistence, migration, dispersal colonization, and evolutionary responses. Similar to sensitivity, it can be also assessed by empirical, model, and observational studies (Nicotra et al., 2015; Beever et al., 2016).

In the present study, we selected representative amphibian species to assess the vulnerability of this taxa to climate change in China. We hope our results can provide useful information to determine the prior protection levels of amphibians, and provide information related to the extinction risks of different species caused by climate change to policy makers and animal protection departments.

\section{MATERIALS AND METHODS}

\section{Representative Species}

According to Fei et al. (2009), Fei et al. (2012), and the new species published in recent years, there are 585 amphibian species in China by the end of November, 2021. ${ }^{1}$ However, not all the species have large populations in the wild. In ecological studies, species with high abundance in the field are usually selected as representative species to assess the effects of human/natural disturbance on animal communities (Park et al., 2006). Based on this criterion, and also considering some narrow distributed endemic amphibians on mountains, a total of 104 representative species were selected. Specifically, at least one species was selected from each genus, and two to three species were selected from genera that contained more than six species in China (e.g., Scutiger, Rana, and Zhangixalus; Supplementary Table 1).

\section{Vulnerable Factors}

Based on the report of IPCC in 2001, previous studies usually selected factors related to species exposure (e.g., temperature, rainfall changes, and migration barriers), sensitivity (e.g., habitat specificity, interspecific relationship, migration ability, and food diversity), and adaptability (e.g., environmental pollution, human disturbance, future adaptation to habitat change, adaptability to habitat availability, and food availability) to assess the vulnerability of species to climate change (e.g., Bagne et al., 2011; Rowland et al., 2011; Foden et al., 2013; Li et al., 2017). However, recent studies suggested that only considering these criteria cannot completely reflect the vulnerability of organisms to climate change (Fortini and Schubert, 2017). It is also necessary to incorporate factors related to species migration, habitat adaptation, thermal tolerance, and evolution, which reflect the life history response of species to climate change (Foden et al., 2013; Fortini and Schubert, 2017). Following these suggestions, a total of 18 vulnerable factors belonging to five categories (i.e., thermal tolerance, individual reproductive, population diffusion and diversity, food and habitat, and habitat climate conditions) were selected in the present study (Supplementary Table 2).

\footnotetext{
${ }^{1}$ http://www.amphibiachina.org/
} 


\section{Data Acquisition}

All the vulnerable factors were categorical variables. The data of species thermal tolerance, individual reproductive, population diffusion and diversity, food and habitat evaluation were acquired from Fei et al. (2006, 2009, 2012), the published literatures (e.g., Hou et al., 2014; Sung et al., 2016; Wang et al., 2017; Zeng et al., 2017), as well as the experts opinions. Data of habitat climate conditions was extracted from Worldclim database (Version 1.4). ${ }^{2}$ Then, we divided the species vulnerability to each factor into three levels (1: Low vulnerability; 2: Moderate vulnerability; 3: High vulnerability), and the definition of each level related to each vulnerable factor was obtained following the criteria of World Wide Fund for Nature (WWF). ${ }^{3}$ Details of the vulnerable factors and their definitions are as follows (Supplementary Table 2):

\section{Thermal Tolerance}

\section{Thermal Tolerance}

Amphibians have their own thermal tolerance ranges (Khatiwada et al., 2020), which reflect their resilience to temperature change (Bernardo and Spotila, 2006). We scored this factor as:

1-High thermal tolerance (Low vulnerability).

2-Moderate thermal tolerance (Moderate vulnerability).

3-Low thermal tolerance (High vulnerability).

Published information on the thermal tolerance of amphibians in China is very limited. Therefore, our uncertainty scores were determined according to the experts opinions rather than empirical evidences.

\section{Breeding \\ Spawning Sites and Clutch Size}

Amphibians can spawn in different sites such as trees, streams, and ponds (Duellman, 1992). Amphibians can also have varied clutch size, from a few to thousands (Fei et al., 2012). Moreover, these species with distinct spawning sites and diverse clutch size can exhibit a gradient of sensitivity to climate change (Carr et al., 2013; Foden et al., 2013). For instance, the poolbreeding amphibians are highly vulnerable to climate change (Scheele et al., 2012), and species with larger clutch size are of low vulnerability (Combes et al., 2018). Therefore, we defined breeding associated with spawning sites and clutch size as:

1 -Site type of oviposition is land/clutch size is $\geq 1,000$ (Low vulnerability).

2-Site type of oviposition is lotic water and trees/clutch size is between 100 and 1,000 (Moderate vulnerability).

3-Site type of oviposition is lentic water/clutch size is $\leq 100$ (High vulnerability).

\section{Metamorphosis Period \\ Rapidly metamorphic amphibians are less affected by climate change (Semlitsch, 1987; Rowe and Dunson, 1995; Ultsch et al., 1999; Carey and Alexander, 2003; Corn, 2005). This is because species with rapid metamorphosis can avoid death in \\ ${ }^{2}$ http://www.worldclim.org/ \\ ${ }^{3}$ https://www.worldwildlife.org/initiatives/adapting-to-climate-change}

a prolonged drought. Therefore, we defined breeding associated with metamorphosis period as:

1 -Completed the metamorphosis $\leq 3$ months (Low vulnerability).

2-Completed the metamorphosis between 3 and 12 months (Moderate vulnerability).

3-Completed the metamorphosis $\geq 12$ months (High vulnerability).

\section{Maturation Age}

Species with fast sexual maturity are lowly vulnerable. This is because delayed reproduction may increase vulnerability to compete for limited resources when facing extreme conditions. Moreover, recruitment of long maturated species is more relied on long term of suitable conditions to allow their offspring to reach size-based resistance to extreme conditions (Luhring and Holdo, 2015). Hence, we defined breeding associated with maturation age as:

1-The sexual maturity time is $\leq 1$ year
(Low vulnerability).
2-The sexual maturity time is between 1 and 3 years
(Moderate vulnerability).
3-The sexual maturity time is $\geq 3$ years
(High vulnerability).

\section{Food and Habitat}

\section{Feeding}

Temperature rise will increase amphibians metabolic rates, which may subsequently increase their food demands (Li et al., 2013). Therefore, feeding generalists can quickly obtain sufficient food, which will be less affected. However, feeding specialists may be more affected as they strongly relied on specific food items, which may be not easily acquired in the field. According, we defined feeding as:

1 -Feeding generalists (Low vulnerability).

2-Between feeding specialists and generalists (Moderate vulnerability).

3-Feeding specialists (High vulnerability).

\section{Abundance of Potential Food Resources}

Climate change could indirectly affect amphibians survival rate and reproductive success via changing the abundance of food resources (Gouveia et al., 2013). Therefore, this item was considered as:

1-Wide range of food resources (Low vulnerability).

2-Moderate range of food resources (Moderate vulnerability).

3-Limited food resources (High vulnerability).

\section{Primary Habitat}

Arboreal type species can better adapt to drier conditions through the variation of body shape (Castro et al., 2021). However, increasing temperature may easily impact body condition and decrease the survival of terrestrial/water type species, such as Bufo bufo (Reading, 2007), Xenopus laevis (Ruthsatz et al., 2018), 
and Rana cascadae (Kissel et al., 2019). Accordingly, we defined primary habitat as:

1-Arboreal type species (Low vulnerability).

2-Terrestrial type species (Moderate vulnerability).

3-Water type species (High vulnerability).

\section{Habitat Type Diversity}

Climate change induced habitat loss leading to the decline of amphibian populations (Li et al., 2013). Amphibians with more habitat types may be less effected by climate change. Therefore, we defined habitat type diversity as:

1-High diversity of habitat types (Low vulnerability).

2-Moderate diversity of habitat types (Moderate vulnerability).

3-Low diversity of habitat types (High vulnerability).

\section{Population Status \\ Population Size}

Amphibians with small populations are greatly affected by climate change. This is because populations of these species can be hardly restored once they declined due to climate change. Hence, we defined population size as:

1-Large population size (Low vulnerability).

2-Moderate population size (Moderate vulnerability).

3-Small population size (High vulnerability).

\section{Population Distribution}

Species with larger distribution range usually exhibit stronger environmental tolerance (Khatiwada et al., 2020), which can be considered as low vulnerability. Therefore, we defined populations distribution as:

1-Large distribution range (Low vulnerability).

2-Moderate distribution range (Moderate vulnerability).

3-Small distribution range (High vulnerability).

\section{Primary Movement Methods}

Movement methods are related to amphibians migration ability, with swimming species exhibiting the lowest migration ability. And they are more easily affected by climate change (Corn, 2005; Lawler et al., 2009; Warren et al., 2013). Hence, we defined primary movement methods as:

1-Jumping species (Low vulnerability).

2-Climbing and walking species (Moderate vulnerability).

3-Swimming species (High vulnerability).

\section{Genetic Diversity}

Species with low genetic diversity have fewer new characteristics that can adapt to new climatic conditions (Foden and Young, 2016). Therefore, we defined genetic diversity as:

1-High genetic diversity of species (Low vulnerability).

2-Moderate genetic diversity of species (Moderate vulnerability).

3-Low genetic diversity of species (High vulnerability).

\section{Breeding Migration}

Some amphibian species in temperate regions migrate from terrestrial habitats to aquatic habitats for short-term reproduction (Duellman and Trueb, 1985). Since rainfall plays a crucial role in determining amphibians breeding migrations (Greenberg and Tanner, 2004; Arnfield et al., 2012), climate change may cause stronger effects on these species. Thus, we defined breeding migration as:

1-Species without migration behavior (Low vulnerability).

3-Species with migration behavior in the breeding period (High vulnerability).

\section{Habitat Climate Conditions}

\section{Extent to Which Species Is Currently Exposed to Climate Variability}

Species distributed in areas that have been strongly affected by climate change (e.g., Qinghai-Tibet Plateau) could be more easily affected (Zhou et al., 2014). Therefore, we defined the extent to which species is currently exposed to climate variability as:

1-Low levels of the extent to which species is currently exposed to climate variability (Low vulnerability).

2-Moderate levels of the extent to which species is currently exposed to climate variability (Moderate vulnerability).

3-High levels of the extent to which species is currently exposed to climate variability (High vulnerability).

\section{Extent to Which Air Temperature Is Expected to Change Within the Range of Species Distribution}

Species distributed in areas with high variability of air temperature (e.g., tropics and plains) may be more susceptible (Collins and Storfer, 2003; Toranza and Maneyro, 2014). Thus, we defined this item as:

1-Low levels of the extent to which air temperature is expected to change within the range of species distribution (Low vulnerability).

2-Moderate levels of the extent to which air temperature is expected to change within the range of species distribution (Moderate vulnerability).

3-High levels of the extent to which air temperature is expected to change within the range of species distribution (High vulnerability).

\section{Extent to Which Precipitation Is Expected to Change Within the Range of Species Distribution}

Species distributed in areas with high levels of precipitation variability (e.g., eastern China) may be more easily affected (Chen S. et al., 2011). Hence, we defined it as:

1-Low levels of the extent to which precipitation is expected to change within the range of species distribution (Low vulnerability).

2-Moderate levels of the extent to which precipitation is expected to change within the range of species distribution (Moderate vulnerability). 
3-High levels of the extent to which precipitation is expected to change within the range of species distribution (High vulnerability).

\section{Other Threat Factors}

There are many others threats for amphibians, including habitat loss, habitat alteration, and pollution, etc. (Alford and Richards, 1999; Pimm and Raven, 2000; Collins and Storfer, 2003; Stuart et al., 2004). Species with less effects of these factors can be considered as low vulnerability. These were mainly determined according to the experts opinions as follows:

1-Low levels of other threat factors (Low vulnerability). 2-Moderate levels of other threat factors (Moderate vulnerability).

3-High levels of other threat factors (High vulnerability).

\section{Statistical Analyses}

Two approaches are incorporated to assess the vulnerability of amphibians to climate change in China. First, the climate change vulnerability index was calculated for each species based on the formula as follows:

$$
V I=\prod_{i=1}^{k}\left(\sum_{i=1}^{n} V F_{i}\right)
$$

where $V I$ is the vulnerability index (the larger the value, the higher the vulnerability), $V F_{i}$ is the criterion of each category, $n$ is the total number of factors within each category, and $k$ is the total number of categories. After that, natural breaks analyses were used to determine the vulnerability of 104 species to climate change following Gardali et al. (2012). Second, a principal coordinate analysis (PCoA; Gower, 1966) based on the BrayCurtis index of the distance matrix created by Euclidean distance between species was conducted following Villéger et al. (2008). PC axes with their eigenvalue $\geq 1$ were selected to construct a multi-dimensional vulnerability space. Then, $k$-means cluster analyses were carried out according to the distribution of all species in the space. Finally, according to the method provided by Gardali et al. (2012), the two results for each species were integrated by using the comprehensive list matrix to determine the vulnerability for each species (Table 1).

\section{RESULTS}

According to the International Union for Conservation of Nature (IUCN) red list, the 104 representative amphibian species included one Extinct (ET), three Critically Endangered (CR), eight Endangered (EN), 11 Vulnerable (VU), five Near Threatened (NT), 54 Least Concern (LC), and 22 No Evaluated/Data Deficient (NE/DD).

\section{Results Based on Natural Breaks}

The results from species vulnerability index and natural breaks analyses indicated that 54 species belonged to the low vulnerability type (e.g., F. multistriata, Hoplobatrachus chinensis, Rhacophorus bipunctatus, Rana omeimontis, and
Oreolalax major), accounting for $51.92 \%$ of all the studied species. 41 species were moderate vulnerability type (e.g., A. davidianus, Rana kukunoris, Hynobius chinensis, Amolops granulosus, and Scutiger glandulatus), accounting for $39.42 \%$ of all the studied species. And nine species were high vulnerability type (e.g., Glyphoglossus yunnanensis, Cynops wolterstorffi, Amolops medogensi, Batrachuperus pinchonii, Glandirana emeljanovi, Hylarana cubitalis, Pachyhynobius shangchengensis, Odorrana zhaoi, and Onychodactylus zhangyapingi; Supplementary Table 3), accounting for $8.65 \%$ of all the studied species.

\section{Results Based on PCoA and $k$-Means Cluster Analyses}

The first four principal components had their eigenvalue $\geq 1$, which explained $55 \%$ of the total inertia $(\mathrm{PC} 1=21.13 \%$, PC2 $=14.40 \%$, PC3 $=10.96 \%$, PC4 $=8.51 \%)$. Specifically, PC1 was mainly positively correlated with spawning sites, but negatively correlated with clutch size, metamorphosis period, maturation age, habitat type diversity, population size, population distribution, and genetic diversity. PC2 was mainly positively correlated with thermal tolerance, metamorphosis period, maturation age, extent to which species is currently exposed to climate variability, extent to which air temperature is expected to change within the range of species distribution, and negatively correlated with extent to which precipitation is expected to change within the range of species distribution. PC3 was mainly positively correlated with primary movement methods, but negatively correlated with metamorphosis period. In addition, the interpretation rate of each factor to PC4 was relatively small ( $<50 \%$; Supplementary Table 4 and Figure 1).

The results of $k$-means cluster analyses indicated that 61 species (e.g., R. kukunoris, R. omeimontis, Pelophylax plancyi, Tylototriton kweichowensis, F. multistriata, O. major, and Hoplobatrachus chinensis) were low vulnerable species, accounting for $58.65 \%$ of all the studied species. 38 species (e.g., Hynobius chinensis, A. davidianus, G. minima, A. granulosus, S. glandulatus, and G. yunnanensis) were moderately vulnerable species, accounting for $36.54 \%$ of the total studied species. Finally, five species (i.e., Ichthyophis kohtaoensis, K. eiffingeri, T. corticale, R. bipunctatus, and Zhangixalus prasinatus; Supplementary Table 3) were highly vulnerable species, accounting for $4.8 \%$ of the total species.

\section{The Integrated Results Based on Two Approaches}

Comprehensive list matrix was created according to the integrated results from the two approaches. Our results demonstrated that 36 species were finally classified as low vulnerability type (e.g., F. multistriata, O. major, R. omeimontis, and Hoplobatrachus chinensis). 54 species were moderate vulnerability (e.g., A. davidianus, Hynobius chinensis, R. kukunoris, G. minima, and A. granulosus). And 14 species were high vulnerability (i.e., I. kohtaoensis, P. shangchengensis, B. pinchonii, O. zhangyapingi, C. wolterstorff, Glandirana emeljanovi, Hylarana cubitalis, A. medogensi, O. zhaoi, 

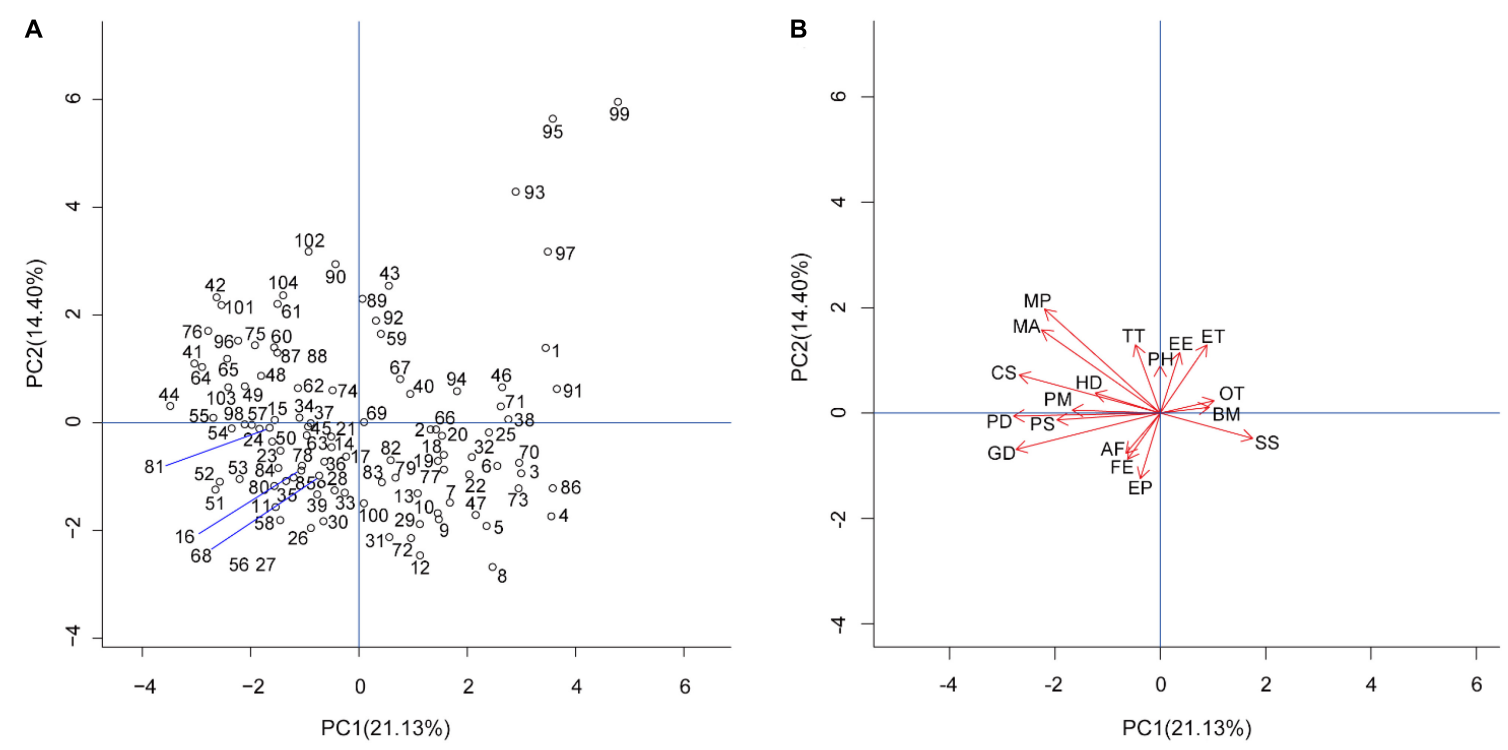

FIGURE 1 | Principal coordinate analysis of 104 species and 18 vulnerable factors. (A) Distribution of the 104 species. (B) Contribution of the 18 vulnerable factors. Codes of species are in Supplementary Table 1. Abbreviation of vulnerable factors are as follows: MP, metamorphosis period; MA, maturation age; CS, clutch size; $\mathrm{HD}$, habitat type diversity; PM, primary movement methods; PD, population distribution; PS, population size; GD, genetic diversity; AF, abundance of potential food resources; FE, feeding; EP, extent to which precipitation is expected to change within the range of species distribution; SS, spawning sites; BM, breeding migration; OT, other threats factors; ET, extent to which air temperature is expected to change within the range of species distribution; EE, extent to which species is currently exposed to climate variability; $\mathrm{PH}$, primary habitat; TT, thermal tolerance.

K. eiffingeri, T. corticale, R. bipunctatus, Z. prasinatus, and G. yunnanensis; Supplementary Table 3).

\section{DISCUSSION}

The selection of representative species was considered to be feasible to study the response of animal groups to the natural/human induced disturbance (Park et al., 2006). In the present study, 104 representative species were selected from amphibians in China (at least one for each genus, and two to three were selected from genera that contained more than six species; e.g., Scutiger, Rana, and Zhangixalus) to investigate the vulnerability of this taxa to climate change by using the combination of two approaches. Our results indicated that 14 species were highly vulnerable to climate change, with most of them distributing in low latitude areas. For instance,

TABLE 1 | Matrix that integrates the ranks of amphibians vulnerability to climate change from natural breaks and $k$-means cluster analyses.

\begin{tabular}{llll}
\hline \multicolumn{4}{c}{ Integrative rank } \\
\hline & \multicolumn{3}{c}{ K-means cluster rank } \\
\cline { 2 - 4 } Natural breaks rank & 1 & 2 & 3 \\
\hline 1 & $\mathbf{1}$ & $\mathbf{2}$ & $\mathbf{3}$ \\
2 & $\mathbf{2}$ & $\mathbf{2}$ & $\mathbf{3}$ \\
3 & $\mathbf{3}$ & $\mathbf{3}$ & $\mathbf{3}$ \\
\hline
\end{tabular}

1, low vulnerability; 2, moderate vulnerability; 3, high vulnerability.
I. kohtaoensis, H. cubitalis, C. wolterstorffi, T. corticale, and G. yunnanensis are mainly distributed in Yunnan, Guangxi, Guangdong, and Hainan, while $Z$. prasinatus is only distributed in Taiwan. And A. medogensis and O. zhaoi are distributed in Moto, Tibet. Therefore, our results supported the claims that species in low latitude areas were more vulnerable to climate change (Deutsch et al., 2008). This is because species at lower latitudes always live at optimum temperature, they thus are more sensitive to temperature changes (Deutsch et al., 2008). Within the 14 high vulnerability species, five species (36\%) were endemic, and most of their IUCN categories were above NT. This result is consistent with Li et al. (2013), suggesting that the endemic and endangered species were more vulnerable to climate change because of their narrow distribution and small populations. In the present study, most of these species are distributed in the eastern Qinghai-Tibet plateau and Hengduan mountains, which exhibited specific habitats. For instance, C. wolterstorffi preferred shallow water bodies around Dianchi Lake, in which had abundant aquatic plants and plankton (He, 1998). Furthermore, $O$. zhaoi can survive and reproduce only under the habitat conditions of small montane streams and small waterfalls (Fei et al., 2012). The effects of climate change on these species could be the reduction of body length (Sheridan and Bickford, 2011), migration to suitable habitats (Duan et al., 2016), and faster metamorphosis. At the same time, climate change (e.g., drought, flood, and high temperature) will also lead to strong changes in habitat characteristic (McMenamin et al., 2008) and food sources (Donnelly and Crump, 1998) of other high vulnerability species such as I. kohtaoensis, P. shangchengensis, B. pinchonii, and $O$. zhangyapingi, resulting in a decline in their populations. 
There were 54 moderately vulnerable species, probably because the life history traits of these species may be able to cope with the impact of climate change within a certain range (Naya et al., 2011). This is because some species, such as Polypedates megacephalus and Bufotes pewzowi, can be in response to climate change through more evolved reproductive patterns (e.g., laying eggs on the land/tree; Li and Jiang, 2016, and larger clutch sizes; Fei et al., 2012). Overall, 68 species (about $65 \%$ of the total number of studied species) were assessed as high and moderate vulnerability to climate change, indicating that climate change has a strong impact on amphibians in China, which may be one of the main reasons causing the decline of amphibian populations ( $\mathrm{Wu}$ and $\mathrm{Li}, 2004$ ). More importantly, the IUCN categories of 20 out of these 68 species were above VU. Since conservation should be conducted for endemic and/or endangered species with limited individuals in the field (Myers et al., 2000; Kier et al., 2009), we suggested that the following eight species should also be considered in future climate change studies (i.e., A. davidianus, G. minima, Echinotriton chinhaiensis, Ranodon sibiricus, H. chinensis, Rana sauteri, Liuixalus ocellatus, and Parapelophryne scalpta).

Overall, our study investigated that more than $60 \%$ of the amphibians (i.e., high and moderate vulnerability) were strongly affected by climate change in China. This can be attributed to these species specific life history traits, population status, and habitat conditions. According, these species, in particular highly vulnerable species, should be the priority in future conservation activities. In recent decades, a growing number of natural reserves have been established in China to protect amphibians. However, since the climate condition of habitats may be no longer suitable for amphibians due to climate change in the future, more work (e.g., the adjustment of natural reserves in time) is still needed ( $\mathrm{Ma}$ and Jiang, 2005). More importantly, our results also suggested that the vulnerability of climate change research cannot only focus on large vertebrates (e.g., Ailuropoda melanoleuca and Panthera uncia), amphibians should also be considered and better protected in response to future climate change.

\section{REFERENCES}

Alford, R. A., and Richards, S. J. (1999). Global amphibian declines: a problem in applied ecology. Annu. Rev. Ecol. Syst. 30, 133-165. doi: 10.1093/ilar.48.3.270

Arnfield, H., Grant, R., Monk, C., and Uller, T. (2012). Factors influencing the timing of spring migration in common toads (Bufo bufo): timing of spring migration in toads. J. Zool. 288, 112-118. doi: 10.1111/j.1469-7998.2012. 00933.x

Bagne, K. E., Friggens, M. M., and Finch, D. M. (2011). A System for Assessing Vulnerability of Species (SAVS) to Climate Change. Fort Collins, CO: U.S. Department of Agriculture, Forest Service, Rocky Mountain Research Station, doi: 10.2737/RMRS-GTR-257

Beever, E. A., O’Leary, J., Mengelt, C., West, J. M., Julius, S., Green, N., et al. (2016). Improving conservation outcomes with a new paradigm for understanding species' fundamental and realized adaptive capacity: a new paradigm for defining adaptive capacity. Cons. Lett. 9, 131-137. doi: 10.1111/conl.12190

Bellard, C., Bertelsmeier, C., Leadley, P., Thuiller, W., and Courchamp, F. (2012). Impacts of climate change on the future of biodiversity: biodiversity and climate change. Ecol. Lett. 15, 365-377. doi: 10.1111/j.1461-0248.2011.01736.x

\section{DATA AVAILABILITY STATEMENT}

The raw data supporting the conclusions of this article will be made available by the authors, without undue reservation.

\section{ETHICS STATEMENT}

The animal study was reviewed and approved by the Animal Care and Use Committee of Chengdu Institute of Biology.

\section{AUTHOR CONTRIBUTIONS}

TZ contributed to the development of ideas. TZ and CZ analyzed the data and wrote the first draft of the manuscript. All authors approved the final version of the manuscript.

\section{FUNDING}

This study was supported by the Second Tibetan Plateau Scientific Expedition and Research Program (STEP) (Grant No. 2019QZKK0501), the China Biodiversity Observation Networks (Sino BON), and WWF China (10002399).

\section{ACKNOWLEDGMENTS}

We are thankful to Liming Chang, Meihua Zhang, Xungang Wang, and Wenbo Zhu for data collection.

\section{SUPPLEMENTARY MATERIAL}

The Supplementary Material for this article can be found online at: https://www.frontiersin.org/articles/10.3389/fevo.2022. 826910/full\#supplementary-material

Bernardo, J., and Spotila, J. R. (2006). Physiological constraints on organismal response to global warming: mechanistic insights from clinally varying populations and implications for assessing endangerment. Biol. Lett. 2, 135-139. doi: $10.1098 / \mathrm{rsbl} .2005 .0417$

Carey, C., and Alexander, M. A. (2003). Climate change and amphibian declines: is there a link? Divers. Distrib. 9, 111-121. doi: 10.1046/j.1472-4642.2003. 00011.x

Carr, J. A., Outhwaite, W. E., Goodman, G. L., Oldfield, T. E. E., and Foden, W. B. (2013). Vital but Vulnerable: Climate Change Vulnerability and Human use of Wildlife in Africa's Albertine Rift, Occasional Paper of the IUCN Species Survival Commission No. 48. Gland: IUCN, xii+224.

Castro, K. M. S. A., Amado, T. F., Olalla-Tárraga, M. A., Gouveia, S. F., Navas, C. A., and Martinez, P. A. (2021). Water constraints drive allometric patterns in the body shape of tree frogs. Sci. Rep. 11:1218. doi: 10.1038/s41598-020-80456-1

Chen, I. C., Hill, J. K., Ohlemüller, R., Roy, D. B., and Thomas, C. D. (2011). Rapid range shifts of species associated with high levels of climate warming. Science 333, 1024-1026. doi: 10.1126/science.1206432

Chen, S., Jiang, G., Zhang, J., Li, Y., and Qian, H. (2011). Species turnover of amphibians and reptiles in eastern China: disentangling the relative effects 
of geographic distance and environmental difference. Ecol. Res. 26, 949-956. doi: 10.1007/s11284-011-0850-3

Collins, J. P., and Storfer, A. (2003). Global amphibian declines: sorting the hypotheses. Divers. Distrib. 9, 89-98. doi: 10.1046/j.1472-4642.2003.00012.x

Combes, M., Pinaud, D., Barbraud, C., Trotignon, J., and Brischoux, F. (2018). Climatic influences on the breeding biology of the agile frog (Rana dalmatina). Sci. Nat. 105:5. doi: 10.1007/s00114-017-1530-0

Corn, P. S. (2005). Climate change and amphibians. Anim. Biodiv. Cons. 28, 59-67.

Dawson, T. P., Jackson, S. T., House, J. I., Prentice, I. C., and Mace, G. M. (2011). Beyond predictions: biodiversity conservation in a changing climate. Science 332, 53-58. doi: 10.1126/science.1200303

Deutsch, C. A., Tewksbury, J. J., Huey, R. B., Sheldon, K. S., Ghalambor, C. K., Haak, D. C., et al. (2008). Impacts of climate warming on terrestrial ectotherms across latitude. Proc. Nati. Acad. Sci. U.S.A. 105, 6668-6672. doi: 10.1073/pnas. 0709472105

Donnelly, M. A., and Crump, M. L. (1998). Potential effects of climate change on two neotropical amphibian assemblages. Clim. Change 39, 541-561.

Duan, R., Kong, X., Huang, M., Varela, S., and Ji, X. (2016). The potential effects of climate change on amphibian distribution, range fragmentation and turnover in China. PeerJ 4:e2185. doi: 10.7717/peerj.2185

Duellman, W. E. (1992). Reproductive strategies of frogs. Sci. Am. 279, 80-87. doi: 10.1038 /scientificamerican0792-80

Duellman, W. E., and Trueb, L. (1985). Biology of Amphibians. New York, NY: McGraw-Hill Book Company Press.

Elmqvist, T., Fragkias, M., Goodness, J., Güneralp, B., Marcotullio, P. J., McDonald, R. I., et al. (2013). Urbanization, Biodiversity and Ecosystem Services: Challenges and Opportunities. New York, NY: Springer Netherlands Press.

Fei, L., Hu, S. Q., Ye, C. Y., and Huang, Y. Z. (2006). Fauna Sinica (Amphibia I). General Accounts of Amphibia, Gymnophiona and Urodela. Beijing: Science Press. In Chinese.

Fei, L., Hu, S. Q., Ye, C. Y., and Huang, Y. Z. (2009). Fauna Sinica (Amphibia 2): Anura. Beijing: Science Press. In Chinese.

Fei, L., Ye, C. Y., and Jiang, J. P. (2012). Colored Atlas of Chinese Amphibians and Their Distributions. Chengdu: Sichuan Publishing House of Science and Technology. In Chinese.

Foden, W. B., and Young, B. E. (2016). IUCN SSC Guidelines for Assessing Species' Vulnerability to Climate Change. Version 1.0. Occasional Paper of the IUCN Species Survival Commission No. 59. Cambridge: IUCN Species Survival Commission, $\mathrm{x}+114$.

Foden, W. B., Butchart, S. H. M., Stuart, S. N., Vié, J. C., Akçakaya, H. R., Angulo, A., et al. (2013). Identifying the world's most climate change vulnerable species: a systematic trait-based assessment of all birds, amphibians and corals. PLoS One 8:e65427. doi: 10.1371/journal.pone.0065427

Fortini, L., and Schubert, O. (2017). Beyond exposure, sensitivity and adaptive capacity: a response based ecological framework to assess species climate change vulnerability. Clim. Change Responses 4:2. doi: 10.1186/s40665-017-0030-y

Gao, X., Jin, C. N., Camargo, A., and Li, Y. M. (2015). Allocation trade-off under climate warming in experimental amphibian populations. PeerJ 3:e1326. doi: 10.7717/peerj.1326

Gardali, T., Seavy, N. E., DiGaudio, R. T., and Comrack, L. A. (2012). A climate change vulnerability assessment of California’s at-risk birds. PLoS One 7:e29507. doi: 10.1371/journal.pone. 0029507

Gaston, K. J., Davies, Z. G., and Edmondson, J. L. (2010). "Urban environments and ecosystem functions," in the Urban Ecology, ed. K. J. Gaston (Cambridge: Cambridge University Press), 35-52. doi: 10.1017/CBO9780511778483.004

Gouveia, S. F., Hortal, J., Cassemiro, F. A. S., Rangel, T. F., and Diniz-Filho, J. A. F. (2013). Nonstationary effects of productivity, seasonality, and historical climate changes on global amphibian diversity. Ecography 36, 104-113. doi: 10.1111/j.1600-0587.2012.07553.x

Gower, J. C. (1966). Some distance properties of latent root and vector methods used in multivariate analysis. Biometrika 53, 325-338. doi: 10.2307/2333639

Greenberg, C. H., and Tanner, G. W. (2004). Breeding pond selection and movement patterns by eastern spadefoot toads (Scaphiopus holbrookii) in relation to weather and edaphic conditions. J. Herpetol. 38, 569-577.

Grimm, N. B., Faeth, S. H., Golubiewski, N. E., Redman, C. L., Wu, J. G., Bai, X. M., et al. (2008). Global change and the ecology of cities. Science 319, 756-760. doi: $10.1126 /$ science. 1150195
He, X. R. (1998). Cynops wolterstorffi, an analysis of the factors caused its extinction. Sichuan J. Zool. 17, 58-59. In Chinese with English abstract,

Hoegh-Guldberg, O., Mumby, P. J., Hooten, A. J., Steneck, R. S., Greenfield, P., Gomez, E., et al. (2007). Coral reefs under rapid climate change and ocean acidification. Science 318, 1737-1742. doi: 10.1126/science.1152509

Hou, M., Wu, Y. K., Yang, K. L., Zheng, S., Yuan, Z. Y., and Li, P. P. (2014). A missing geographic link in the distribution of the genus Echinotriton (Caudata: Salamandridae) with description of a new species from southern China. Zootaxa 3895, 89-102. doi: 10.11646/zootaxa.3895.1.5

Huang, Y. J., Lu, J. B., Wang, F. T., Lin, Y. H., Liu, L., Mi, H. X., et al. (2017). Predicting the potential geographical distribution of Hainan Odorous Frog (Odorrana hainanensis) in Hainan province by MaxEnt. Chin. J. Zool. 52, 30-41. In Chinese with English abstract,

IUCN (2016). The IUCN red list of threatended species. Gland: IUCN.

Jiang, J. P., Xie, F., Zang, C. X., Cai, L., Li, C., Wang, B., et al. (2016). Assessing the threat status of amphibians in China. Biodivers. Sci. 24, 588-597. doi: 10.17520/ biods. 2015348

Khatiwada, J. R., Zhao, T., and Jiang, J. P. (2020). Variation of body temperature of active amphibians along elevation gradients in eastern Nepal Himalaya. J. Therm. Biol. 92:102653. doi: 10.1016/j.jtherbio.2020.102653

Kier, G., Kreft, H., Lee, T. M., Jetz, W., Ibisch, P. L., Nowicki, C., et al. (2009). A global assessment of endemism and species richness across island and mainland regions. Proc. Nati. Acad. Sci. U.S.A. 106, 9322-9327. doi: 10.1073/ pnas. 0810306106

Kissel, A. M., Palen, W. J., Ryan, M. E., and Adams, M. J. (2019). Compounding effects of climate change reduce population viability of a montane amphibian. Ecol. Appl. 29:e01832. doi: 10.1002/eap.1832

Lawler, J. J., Shafer, S. L., White, D., Kareiva, P., Maurer, E. P., Blaustein, A. R., et al. (2009). Projected climate-induced faunal change in the western Hemisphere. Ecology 90, 588-597. doi: 10.1890/08-0823.1

Li, C., and Jiang, J. P. (2016). Anuran life cycle and habitat preference. Sichuan J. Zool. 35, 950-955. In Chinese with English abstract,

Li, J., Liu, F., Zhang, Y., Xue, Y. D., and Li, D. Q. (2017). Overview of methods for assessing the vulnerability of wildlife to climate change. Acta Ecol. Sin. 37, 6656-6667.

Li, Y., Cohen, J. M., and Rohr, J. R. (2013). Review and synthesis of the effects of climate change on amphibians. Integr. Zool. 8, 145-161. doi: 10.1111/17494877.12001

Lowe, W. H. (2012). Climate change is linked to long-term decline in a stream salamander. Biol. Conserv. 145, 48-53. doi: 10.1016/j.biocon.2011.10.004

Luhring, T. M., and Holdo, R. M. (2015). Trade-offs between growth and maturation: the cost of reproduction for surviving environmental extremes. Oecologia 178, 723-732. doi: 10.1007/s00442-015-3270-1

Ma, R. J., and Jiang, Z. G. (2005). Impact of global climate change on wildlife. Acta Ecol. Sin. 25, 3061-3066.

McMenamin, S. K., Hadly, E. A., and Wright, C. K. (2008). Climatic change and wetland desiccation cause amphibian decline in Yellowstone National Park. Proc. Nati. Acad. Sci. U.S.A. 105, 16988-16993. doi: 10.1073/pnas.0809090105

Myers, N., Mittermeier, R. A., Mittermeier, C. G., da Fonseca, G. A. B., and Kent, J. (2000). Biodiversity hotspots for conservation priorities. Nature 403, 853-858. doi: $10.1038 / 35002501$

Naya, D. E., Veloso, C., Sabat, P., and Bozinovic, F. (2011). Physiological flexibility and climate change: the case of digestive function regulation in lizards. Comp. Biochem. Physiol. A 159, 100-104. doi: 10.1016/j.cbpa.2011.02.005

Nicotra, A. B., Beever, E. A., Robertson, A. L., Hofmann, G. E., and O’Leary, J. (2015). Assessing the components of adaptive capacity to improve conservation and management efforts under global change: assessing components of adaptive capacity. Cons. Biol. 29, 1268-1278. doi: 10.1111/cobi.12522

Park, Y. S., Tison, J., Lek, S., Giraudel, J. L., Coste, M., and Delmas, F. (2006). Application of a self-organizing map to select representative species in multivariate analysis: a case study determining diatom distribution patterns across France. Ecol. Inform. 1, 247-257. doi: 10.1016/j.ecoinf.2006.03.005

Parmesan, C. (2007). Influences of species, latitudes and methodologies on estimates of phenological response to global warming. Glob. Chang. Biol. 13, 1860-1872. doi: 10.1111/j.1365-2486.2007.01404.x

Pimm, S. L., and Raven, P. (2000). Extinction by numbers. Nature 403, 843-845. doi: $10.1038 / 35002708$ 
Pounds, J. A., Fogden, M. P. L., and Campbell, J. H. (1999). Biological response to climate change on a tropical mountain. Nature 398, 611-615. doi: 10.1038/ 19297

Reading, C. J. (2007). Linking global warming to amphibian declines through its effects on female body condition and survivorship. Oecologia 151, 125-131. doi: 10.1007/s00442-006-0558-1

Rowe, C. L., and Dunson, W. A. (1995). Impacts of hydroperiod on growth and survival of larval amphibians in temporary ponds of central Pennsylvania, USA. Oecologia 102, 397-403. doi: 10.1007/BF00341351

Rowland, E. L., Davison, J. E., and Graumlich, L. J. (2011). Approaches to evaluating climate change impacts on species: a guide to initiating the adaptation planning process. Environ. Manage. 47, 322-337. doi: 10.1007/ s00267-010-9608-x

Ruthsatz, K., Dausmann, K. H., Drees, C., Becker, L. I., Hartmann, L., Reese, J., et al. (2018). Altered thyroid hormone levels affect body condition at metamorphosis in larvae of (Xenopus laevis). J. Appl. Toxicol. 38, 1416-1425. doi: 10.1002/jat. 3663

Scheele, B. C., Driscoll, D. A., Fischer, J., and Hunter, D. A. (2012). Decline of an endangered amphibian during an extreme climatic event. Ecosphere 3:101. doi: 10.1890/ES12-00108.1

Semlitsch, R. D. (1987). Relationship of pond drying to the reproductive success of the salamander Ambystoma talpoideum. Copeia 1987, 61-69. doi: 10.2307/ 1446038

Sheridan, J. A., and Bickford, D. (2011). Shrinking body size as an ecological response to climate change. Nat. Clim. Change 1, 401-406. doi: 10.1038/ nclimate 1259

Stuart, S. N., Chanson, J. S., Cox, N. A., Young, B. E., Rodrigues, A. S. L., Fischman, D. L., et al. (2004). Status and trends of amphibian declines and extinctions worldwide. Science 306, 1783-1786. doi: 10.1126/science.1103538

Sung, Y. H., Hu, P., Wang, J., Liu, H. J., and Wang, Y. Y. (2016). A new species of Amolops (Anura: Ranidae) from southern China. Zootaxa 4170, 525-538. doi: 10.11646/zootaxa.4170.3.6

Toranza, C., and Maneyro, R. (2014). Potential effects of climate change on the distribution of an endangered species: Melanophryniscus montevidensis (Anura: Bufonidae). Phyllomedusa 12, 97-106. doi: 10.11606/issn.2316-9079.v12i2p 97-106

Ultsch, G. R., Bradford, D. F., and Freda, J. (1999). "Physiology: coping with the environment," in Tadpoles: The Biology of Anuran Larvae, eds R. W. McDiarmid and R. Altig (Chicago, IL: University of Chicago Press), 189-214.

Villéger, S., Mason, N. W. H., and Mouillot, D. (2008). New multidimensional functional diversity indices for a multifaceted framework in functional ecology. Ecology 89, 2290-2301. doi: 10.1890/07-1206.1

Wake, D. B., and Vredenburg, V. T. (2008). Are we in the midst of the sixth mass extinction? A view from the world of amphibians. Proc. Nati. Acad. Sci. U.S.A. 105, 11466-11473. doi: 10.1073/pnas.0801921105
Wang, C. C., Qian, L. F., Zhang, C. L., Guo, W. B., Pan, T., Wu, J., et al. (2017). A new species of Rana from the Dabie Mountains in eastern China (Anura, Ranidae). ZooKeys 724, 135-153. doi: 10.3897/zookeys.724.19383

Wang, G., and Feng, X. (2013). The effects of climate change on amphibians. China Nat. 3, 7-9. In Chinese with English abstract,

Warren, R., VanDerWal, J., Price, J., Welbergen, J. A., Atkinson, I., RamirezVillegas, J., et al. (2013). Quantifying the benefit of early climate change mitigation in avoiding biodiversity loss. Nat. Clim. Change 3, 678-682. doi: $10.1038 /$ nclimate 1887

Williams, S. E., Shoo, L. P., Isaac, J. L., Hoffmann, A. A., and Langham, G. (2008). Towards an integrated framework for assessing the vulnerability of species to climate change. PLoS Biol. 6:e325. doi: 10.1371/journal.pbio.0060325

Wu, Z. J., and Li, Y. (2004). Causes and conservation strategies of amphibian population declination. Chinese J. Ecol. 23, 140-146. In Chinese with English abstract,

Zeng, Z. C., Zhao, J., Chen, C. Q., Chen, G. L., Zhang, Z., and Wang, Y. Y. (2017). A new species of the genus Gracixalus (Amphibia: Anura: Rhacophoridae) from Mount Jinggang, southeastern China. Zootaxa 4250, 171-185. doi: 10.11646/ zootaxa.4250.2.3

Zhao, T., Zhang, W. Y., Zhou, J., Zhao, C. L., Liu, X. K., Liu, Z. D., et al. (2020). Niche divergence of evolutionarily significant units with implications for repopulation programs of the world's largest amphibians. Sci. Total Environ. 738:140269. doi: 10.1016/j.scitotenv.2020.140269

Zhou, W. W., Zhang, B. L., Chen, H. M., Jin, J. Q., Yang, J. X., Wang, Y. Y., et al. (2014). DNA barcodes and species distribution models evaluate threats of global climate changes to genetic diversity: a case study from Nanorana parkeri (Anura: Dicroglossidae). PLoS One 9:e103899. doi: 10.1371/journal. pone.0103899

Conflict of Interest: The authors declare that the research was conducted in the absence of any commercial or financial relationships that could be construed as a potential conflict of interest.

Publisher's Note: All claims expressed in this article are solely those of the authors and do not necessarily represent those of their affiliated organizations, or those of the publisher, the editors and the reviewers. Any product that may be evaluated in this article, or claim that may be made by its manufacturer, is not guaranteed or endorsed by the publisher.

Copyright (c) 2022 Zhao, Jiang, Xie, Li and Zhao. This is an open-access article distributed under the terms of the Creative Commons Attribution License (CC BY). The use, distribution or reproduction in other forums is permitted, provided the original author(s) and the copyright owner(s) are credited and that the original publication in this journal is cited, in accordance with accepted academic practice. No use, distribution or reproduction is permitted which does not comply with these terms. 